\title{
Minimal selective concentrations of tetracycline in complex aquatic bacterial biofilms
}

\author{
Sara V. Lundström a , Marcus Östman ${ }^{\mathrm{b}}$, Johan Bengtsson-Palme ${ }^{\mathrm{a}}$, Carolin Rutgersson ${ }^{\mathrm{a}}$, Malin Thoudal ${ }^{\mathrm{a}}$, \\ Triranta Sircar ${ }^{\mathrm{c}}$, Hans Blanck ${ }^{\mathrm{c}}$, K. Martin Eriksson ${ }^{\mathrm{d}}$, Mats Tysklind ${ }^{\mathrm{b}}$, Carl-Fredrik Flach ${ }^{\mathrm{a}}$, D.G. Joakim Larsson ${ }^{\mathrm{a}, *}$ \\ a Department of Infectious Diseases, Institute for Biomedicine, Sahlgrenska Academy, University of Gothenburg, Sweden \\ b Department of Chemistry, Umeå University, Sweden \\ c Department of Biological and Environmental Sciences, University of Gothenburg, Sweden \\ ${ }^{\mathrm{d}}$ Department of Shipping and Marine Technology, Chalmers University of Technology, Sweden
}

\section{H I G H L I G H T S}

- Methods to determine minimal selective concentrations of antibiotics were compared.

- One $\mu \mathrm{g} / \mathrm{L}$ tetracycline selects for tetA and tet $G$ genes in freshwater biofilms.

- Ten $\mu \mathrm{g} / \mathrm{L}$ tetracycline selects for phenotypic resistance.

- Selective concentrations overlap with those reported in sewage treatment plants.

- Approach described could be used in risk assessment of other antibiotics as well.

\section{G R A P H I C A L A B S T R A C T}

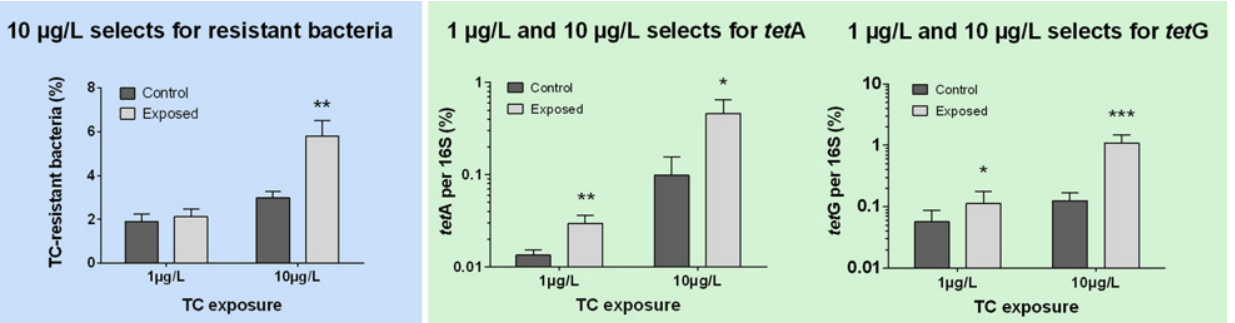

\section{A R T I C L E I N F O}

\section{Article history:}

Received 30 October 2015

Received in revised form 15 February 2016

Accepted 15 February 2016

Available online 22 March 2016

Editor: D. Barcelo

\section{Keywords:}

Minimal selective concentration

Antibiotic resistance

Risk assessment

Antibiotic contaminants

Environmental emission limits

\begin{abstract}
A B S T R A C T
Selection pressure generated by antibiotics released into the environment could enrich for antibiotic resistance genes and antibiotic resistant bacteria, thereby increasing the risk for transmission to humans and animals. Tetracyclines comprise an antibiotic class of great importance to both human and animal health. Accordingly, residues of tetracycline are commonly detected in aquatic environments. To assess if tetracycline pollution in aquatic environments promotes development of resistance, we determined minimal selective concentrations (MSCs) in biofilms of complex aquatic bacterial communities using both phenotypic and genotypic assays. Tetracycline significantly increased the relative abundance of resistant bacteria at $10 \mu \mathrm{g} / \mathrm{L}$, while specific tet genes (tetA and tetG) increased significantly at the lowest concentration tested $(1 \mu \mathrm{g} / \mathrm{L})$. Taxonomic composition of the biofilm communities was altered with increasing tetracycline concentrations. Metagenomic analysis revealed a concurrent increase of several tet genes and a range of other genes providing resistance to different classes of antibiotics (e.g. cmlA, floR, sul1, and mphA), indicating potential for co-selection. Consequently, MSCs for the tet genes of $\leq 1 \mu \mathrm{g} / \mathrm{L}$ suggests that current exposure levels in e.g. sewage treatment plants could be sufficient to promote resistance. The methodology used here to assess MSCs could be applied in risk assessment of other antibiotics as well.
\end{abstract}

(c) 2016 Elsevier B.V. All rights reserved.

Abbreviations: ARG, antibiotic resistance gene; CFU, colony forming unit; EC50, concentration at 50\% effect; LC-MS/MS, liquid chromatography-tandem mass spectrometry; MIC, minimal inhibitory concentration; MSC, minimal selective concentration; PICT, pollution-induced community tolerance; qPCR, quantitative polymerase chain reaction; TC, tetracycline.

* Corresponding author at: Department of Infectious Diseases, Institute of Biomedicine, University of Gothenburg, Guldhedsgatan $10 \mathrm{~A}$, SE-413 46 Gothenburg, Sweden.

E-mail address: joakim.larsson@fysiologi.gu.se (D.G.J. Larsson). 


\section{Introduction}

Antibiotic resistance genes (ARGs) have been present in the environment long before humans started using antibiotics to treat bacterial infections (D'Costa et al., 2011). However, after introduction of antibiotics as clinical agents, ARGs have become very common in human pathogens. External environments host a vast diversity of bacteria, much larger than that found in and on our bodies. Thus, the environmental resistome most likely contains many rare or undiscovered ARGs, that under a sufficient selection pressure from antibiotics could be enriched, mobilized, and end up in pathogens, which most likely have happened with many ARGs in the past (Davies and Davies, 2010).

Widespread use and misuse of antibiotics over the past 70 years has been accompanied by unintentional environmental pollution of antibiotics. Thus, there is a potential for antibiotics to cause selection pressures in humans and animals undergoing therapy, but also in every environment impacted by our waste. Measured concentrations of antibiotics in aquatic environments range from $\mathrm{ng}$ to $\mu \mathrm{g} / \mathrm{L}$ as a result of excretion from humans and animals (Watkinson et al., 2009; Segura et al., 2009; Rizzo et al., 2013) while levels as high as mg/L have been detected as a consequence of direct pollution from drug manufacturing (Larsson, 2014). Determining the concentrations of antibiotics that are selective for resistance is crucial for identifying environments where increase of ARGs are predicted to occur and measures need to be taken to minimize such an increase (Ashbolt et al., 2013; Pruden et al., 2013; Brandt et al., 2015).

Tetracycline (TC) antibiotics are one of the most commonly used antibiotic classes, primarily due to their broad activity spectrum and low cost. Consumption of TCs by animals and humans in the European Union is estimated at thousands of tons each year (Kools et al., 2008; Coenen et al., 2011). Since up to $75 \%$ of consumed TCs are excreted in their active forms (Elmund et al., 1971; Agwuh and MacGowan, 2006), large amounts of TCs reach aquatic environments.

Two previous studies have reported the minimal selective concentration (MSC) of TC using two competing strains, which differ only in two aspects. They contain different marker gene(s) and the resistant strain has a transposon ( $\operatorname{Tn} 10)$, containing tetA. Liu et al. (2011) reported a MSC for TC of $62.5 \mu \mathrm{g} / \mathrm{L}$, and later that year Gullberg et al. (2011) reported a somewhat lower MSC for TC of $15 \mu \mathrm{g} / \mathrm{L}$. Discrepancies between these two MSCs may be due to differences in test strains, fitness cost, and/or sensitivity of the detection system. These studies demonstrate the ability of TC to select for a specific resistance factor in a highly simplified competition situation. Environments polluted with TCs, such as surface waters, sediments, and sewage treatment plants, contain much more complex communities with a large diversity of bacterial species and ARGs. In such communities there are ample possibilities for a range of species and strains to fill the ecological niches made available through an added selection pressure. Hence, it is not straightforward to extrapolate the selective potential of an antibiotic to entire communities based on competition experiments with only two strains. Effects of TC on microbial communities have been reported in one study where five stream mesocosms were exposed to different TC concentrations $(0,0.5,1,10,100 \mu \mathrm{g} / \mathrm{L})$ (Quinlan et al., 2011). That study focused on ecotoxicological effects of TC exposure on e.g. bacterial productivity, abundance of algae, and organic biomass. Additionally, this study reported a significant increase of phenotypic TC resistance at $0.5 \mu \mathrm{g} / \mathrm{L}$. However, TC resistance increase did not follow a traditional exposureresponse pattern, as exposure to $0.5 \mu \mathrm{g} / \mathrm{L}$ caused significantly increased TC resistance, whereas 1,10 , and $100 \mu \mathrm{g} / \mathrm{L}$ counterintuitively did not. Therefore, there is a need to clarify the TC exposure-response relationship in complex aquatic communities with regard to selection of TC resistance.

It is not obvious whether a phenotypic, genotypic, or taxonomic endpoint should be used when assessing the selective ability of an antibiotic in a complex microbial community. In the case of infection by a pathogen, phenotypic resistance is crucial for the treatment outcome.
Hence, the ability to select for bacteria tolerating an antibiotic concentration exceeding the clinical breakpoint for a given antibiotic is a reasonable endpoint. However, in an environmental community, treatability is of less concern than e.g. risk for selection of mobilizable genes. Thus, genotypic resistance could be equally (or even more) relevant to study. It is of particular concern that novel ARGs could become enriched, mobilized, and transferred to pathogens (Bengtsson-Palme and Larsson, 2015). Detecting such novel ARGs is difficult, but it is reasonable to assume that they are likely to be overrepresented in more tolerant strains. Taxonomic shifts in a bacterial community, following addition of an antibiotic, thus demonstrate that a selection pressure has been exerted on the community and that sensitive strains have been replaced by more tolerant ones (Blanck, 2002). Hence, a taxonomic change is a reflection of a selection pressure that over time could contribute to the development of resistance of clinical concern.

The primary aim of this study was to determine MSCs of TC on a genotypic and phenotypic level in complex aquatic bacterial biofilms. We were also interested in identifying changes in taxonomic composition related to TC exposure. Three experiments were performed. In the first experiment, an exposure-response was established using a 10fold dilution series of TC in order to provide a concentration range in which selection was likely to occur. This experiment also provided an initial evaluation of different endpoints, including taxonomic changes, based on their apparent sensitivity, exposure-response, and experimental/analytical throughput. In the second and third experiments, MSCs were established for selected endpoints using more replicates for suspected selective concentrations based on the initial exposureresponse experiment.

\section{Materials and methods}

\subsection{Set-up for biofilm growth in a flow-through system}

To determine the selective properties of TC in complex aquatic bacterial communities, biofilms were established in aquaria containing different concentrations of TC. The experimental setup was designed with both high sensitivity and relevance in mind. Aquaria were constructed from molded glass $(20 \times 15 \times 20 \mathrm{~cm})$ with an outlet consisting of an inserted glass tube $5 \mathrm{~cm}$ from the bottom. Since glass is relatively inert, biofilms were grown on twenty microscope glass slides (VWR International, USA) held in place by a microscope slide staining rack in soda lime glass (Wheaton ${ }^{\circledR}$, USA). Levels of nutrient as well as experimental time were optimized through several tests to ensure growth of a diverse biofilm at $20^{\circ} \mathrm{C}$ in all TC exposures, which gave sufficient biomass for the endpoint analyses. Biofilms were studied because this is how most environmental bacterial communities grow. Furthermore, it provides a stationary phase (biofilm) in a continuous feed (planktonic phase) allowing for a longer selection time more representative of a long-term exposure as seen in affected environments. Notably, selection can take place on several levels, including effects on growth rate in the planktonic (seeding) and the biofilm communities, as well as selection of those bacteria that has an ability to attach, form and integrate into a biofilm in the presence of an antibiotic. In that sense, we here use the term MSC in a slightly wider meaning than the strictly growth-related definition used by Andersson and Hughes (2014). Since TC exposure was present during the establishment of the biofilm, all bacteria colonizing the slides were exposed, at least initially, without the protective properties of the extracellular polymeric substances (EPS) of a biofilm. Each aquarium had three different inlets consisting of inoculum ( $1 \mathrm{~mL} / \mathrm{min}$, through silicone tubing using PharMed $2.79 \times 0.90$ pumptubing), nutrient $(0.2 \mathrm{~mL} / \mathrm{min}$, in a sterilized flow system through silicone tubing using PharMed $2.54 \times 0.90$ pump-tubing) and TC $(0.035 \mathrm{~mL} / \mathrm{min}$, through polytetrafluoroethylene (PTFE) tubing using PharMed $0.38 \times 0.91$ pump-tubing) supplied through peristaltic pumps (IPC-N pump; Ismatec AB, Switzerland). Inoculum was changed daily and consisted of treated sewage effluent (Ryaverket, Gothenburg, 
Sweden) diluted $100 \times$ in saline to reduce any adverse effect of remaining contaminants. Treated sewage effluent was used as an inoculum as it contains a complex mixture of both pathogenic and environmental bacteria with a relatively high abundance and diversity of resistance genes (Ye and Zhang, 2013; Szczepanowski et al., 2009). Grab samples of sewage effluent were collected from Ryaverket twice during each experiment and stored at $4{ }^{\circ} \mathrm{C}$ in darkness until use. Water quality analysis for the treated sewage effluent collected can be found in Table B1 in Appendix B. Nutrient stock used was $0.1 \times$ diluted R2A broth without starch and magnesium sulfate, which might otherwise reduce the efficiency of TC (resulting in approximately 1/60 R2A broth within the aquaria). TC stocks were mixed in sterile superQ water (Super-Q ${ }^{\circledR}$ Plus, EMD Millipore, USA) using TC hydrochloride (Oxoide AB, UK) while the control aquaria were supplied with sterile superQ water. TC stocks were changed daily during the experiment with as little light exposure as possible to reduce photodegradation of TC. To achieve thorough mixing, a magnet stirrer (IKA, China) and a cross-shaped magnet was used for each aquarium at slow speed. Each aquarium was covered by a lid with a cutout to provide room for the inlet tubing.

Prior to each experiment the aquaria and slide racks were cleaned with water and $70 \%$ ethanol to remove residual biofilms, and exposed to UV light ( $254 \mathrm{~nm}, 15 \mathrm{~W}, 20 \mathrm{~min}$ ) to inactivate any possible TC still present from previous use. Microscope slides were put in the racks using latex gloves to avoid affecting the properties of the glass surface. At the start of each experiment, inoculum, nutrient, and TC stock used for each aquarium was mixed in a volume of $2 \mathrm{~L}$ (reflecting their different flow-rates) and the mixture was added to each aquarium. Aquaria were monitored each day for flow-rates and water temperatures. Furthermore, samples ( $45 \mathrm{~mL}$ ) were taken daily to determine the TC concentration in each aquarium.

In the initial exposure-response experiment a possible range for selectivity for each endpoint was identified using a 10-fold dilution series of TC. Hence, biofilms were established in aquaria with different concentrations of TC $(0,0.1,1,10,100$, and $1000 \mu \mathrm{g} / \mathrm{L})$ in duplicates $(\mathrm{n}=2)$.

Based on the results of the exposure-response experiment, two different MSC experiments were performed comparing two different TC concentrations $(1 \mu \mathrm{g} / \mathrm{L}$ or $10 \mu \mathrm{g} / \mathrm{L})$ to unexposed controls $(\mathrm{n}=6+6$ in each experiment) in order to establish MSCs.

\subsection{Harvesting of biofilms}

On the ninth day of each experiment the biofilms from the microscope slides were collected in a predetermined order excluding the first and last slide in each rack. For each aquarium, three separate technical replicates (pseudo-replicates) were harvested containing biofilm from five slides each. Biofilms were scraped from the glass slides into either $4 \mathrm{~mL}$ saline or a saline and $0.1 \times$ R2A broth $(6: 1)$ mixture. The saline-R2A mixture was used in the exposureresponse experiment since the pollution-induced community tolerance (PICT) analysis required the biofilms to be in a buffer that mimics the nutrient and osmotic conditions in the aquarium. The biofilm slurry was transferred to eppendorf tubes and disrupted through bead beating using a TissueLyser mixer mill (Qiagen, Netherlands) at a frequency of $25.0 \mathrm{~Hz}$ with $5 \mathrm{~mm}$ stainless steel beads (Qiagen, Netherlands) for $3 \mathrm{~min}$.

\subsection{Relative counts of colony forming units as a measurement of resistance}

The disrupted biofilms were diluted in a 10-fold dilution series for each aquarium/technical replicate and plated on R2A agar with or without addition of TC ( $20 \mu \mathrm{g} / \mathrm{mL}$ TC). For each dilution, plating was performed in duplicates during the exposure-response experiment and in triplicates during the two MSC experiments. Plates were left to grow for five days in room temperature and darkness prior to colony counting. Colony forming units (CFUs) for each aquarium and R2A plate (with or without $\mathrm{TC}$ ) was determined using the mean (exposure-response experiment) or median (MSC experiments) of the plate replicates, followed by the median of the technical replicates (three per aquarium). Relative resistance was determined as the percentage of total CFU counts by comparing control and TC plates. In the MSC experiments, the hypothesis of increased resistance on TC plates was tested using a one-tailed Student's $t$-test assuming unequal variance.

\subsection{Minimal inhibition concentrations of isolated strains as a measurement of resistance}

For each aquarium, colonies were randomly selected from the R2A plates without TC and stored at $-80{ }^{\circ} \mathrm{C}$. To determine the minimal inhibitory concentration (MIC), each colony was plated on $\mathrm{MH}$ agar plates (Oxoide $\mathrm{AB}, \mathrm{UK}$ ) and incubated at $30^{\circ} \mathrm{C}$ until one single colony could be isolated (24-72 h). This colony was used to inoculate $\mathrm{MH}$ broth, which was then incubated at $30^{\circ} \mathrm{C}$ overnight or until the cultures could be diluted in accordance of the turbidity of the 0.5 McFarland standard. The diluted bacterial suspension was plated on $\mathrm{MH}$-agar plates using a cotton swab, after which a TC epsilometer test (E-test) strip (0.016-256 mg/L; Biomérieux, France) was applied to the agar surface. Incubation was performed for $24-48 \mathrm{~h}\left(30^{\circ} \mathrm{C}\right)$, depending on bacterial growth. For each aquarium MICs of twenty individual colonies, capable of growing in $\mathrm{MH}$ media, were determined. The results from each TC exposure were grouped (40 MIC/exposure) and the determined MICs were then arranged in three different MIC ranges, grouped as low $(0.016-2 \mu \mathrm{g} / \mathrm{mL})$, medium (3$24 \mu \mathrm{g} / \mathrm{mL})$, and high $(32-256 \mu \mathrm{g} / \mathrm{mL})$.

\subsection{Pollution-induced community tolerance of the established biofilms}

PICT, assessed by inhibition of leucine uptake, was used to estimate the tolerance to TC in the different bacterial communities, using shortterm toxicity tests (Brosche and Backhaus, 2010). Composite biofilm for one aquarium was made by pooling the biofilms for the three technical replicates. The composite biofilm was diluted by addition of $49 \mathrm{~mL}$ of saline and $0.1 \times R 2 A(6: 1)$ to $1 \mathrm{~mL}$ biofilm. For each aquarium, shortterm TC exposure $(0.01,0.032,0.1,0.32,1,3.16,10,31.6$, and $100 \mathrm{mg} / \mathrm{L}$ ) was performed in scintillation vials mixing $1 \mathrm{~mL}$ of the composite biofilm with $100 \mu \mathrm{L}$ TC stocks ( $n=4$ per TC concentration). In addition, eight biotic controls ( $1 \mathrm{~mL}$ biofilm and $100 \mu \mathrm{L}$ superQ water) and four abiotic controls ( $1 \mathrm{~mL}$ biofilm, $100 \mu \mathrm{L}$ superQ water, and $100 \mu \mathrm{L}$ $100 \%$ trichloroacetic acid (TCA)) were made per aquarium. This shortterm exposure was left to incubate for $1 \mathrm{~h}$, after which $50 \mu \mathrm{L}$ leucine solution was added that contained L-[4,5-3H]leucine (specific activity 106.2 Ci/mmol; Perkin Elmer, USA) and L-leucine (Sigma-Aldrich, USA) in a mixture prepared at 1:100 dilution (95 nM total leucine and $0.1 \mu$ Ci per sample). Leucine uptake was allowed for $1 \mathrm{~h}$ and then terminated by addition of $100 \mu \mathrm{L}$ of $100 \%$ TCA. Samples were stored at $-18{ }^{\circ} \mathrm{C}$ for 1-2 months, thawed, transferred to $2 \mathrm{~mL}$ plastic tubes and cleaned by centrifugation $\left(16.000 \times \mathrm{g}\right.$ at $4{ }^{\circ} \mathrm{C}$ for $\left.10 \mathrm{~min}\right)$ washing the pellet twice in $1.5 \mathrm{~mL}$ \% TCA. Thereafter, $0.5 \mathrm{~mL}$ scintillation cocktail (Ultima Gold $^{\mathrm{TM}}$; PerkinElmer, USA) was added to each sample after which the plastic tubes were placed in glass scintillation vials and left overnight before counted in a scintillation counter (Packard Tri-Carb 2900TR; PerkinElmer, USA).

For each aquarium the average disintegration per minute (DPM) values of the abiotic controls (Fig. B1, Appendix B) was subtracted from the DPM values of the other samples, thereby correcting for abiotic leucine uptake. Inhibition of leucine uptake was calculated in relation to the average DPM values of the biotic control samples in each aquarium. Concentration-inhibition curve fits to the experimental data were obtained (Fig. B2, Appendix B) using the probit function in the NLreg software (version 6.6) and the EC50 values were obtained from these curve fits. 


\subsection{Functional diversity of biofilms}

Utilization of different carbon sources was studied to assess functional diversity for each technical replicate (three per aquarium) during the exposure-response experiment. From the disrupted biofilm, $1 \mathrm{~mL}$ was washed twice in phosphate buffer by centrifugation $(5000 \times \mathrm{g}$ for $10 \mathrm{~min}$ ) to avoid contamination with alternative carbon sources. Thereafter, the pellet was resuspended in phosphate buffer to a final volume of $15 \mathrm{~mL}$. From this, $125 \mu \mathrm{L}$ was added in each well of the Biolog EcoPlates (Biolog, Inc., USA). Changes in color due to respiration of carbon, as well as turbidity were monitored by measuring the optical density in SpectraMax 340PC microplate reader (Molecular devices, USA). Utilization of each carbon source was determined as the mean color shift (OD $595 \mathrm{~nm}$ ) after subtracting both the turbidity (OD $700 \mathrm{~nm}$ ) of each well and the color shift in the well with no carbon source (OD $595 \mathrm{~nm}$ ). Optical density data from the third day of incubation were used; values below 0.05 were regarded as noise, and set to zero. Substrate diversity, richness and evenness of the communities were determined using the R package Vegan (Oksanen et al., 2011). Linear regression (with log-transformed TC concentration as explanatory variable) was used to assess the influence of TC exposures on diversity, richness and evenness.

\subsection{DNA extraction}

Samples were prepared by pooling $500 \mu \mathrm{L}$ of each bead-beated technical replicate into one sample per aquarium. Samples were pelleted by centrifugation $(6000 \times \mathrm{g}$ for $5 \mathrm{~min})$ and the supernatants removed and stored at $-20{ }^{\circ} \mathrm{C}$ until DNA extraction with DNeasy Blood \& Tissue kit (Qiagen, Netherlands) according to the protocol for Gram-positive bacteria. Thus, DNA from both Gram-positive and Gram-negative bacteria was collected using this protocol.

\subsection{Sequencing and sequence pre-processing}

Paired-end sequencing libraries $(2 \times 125 \mathrm{bp})$ were prepared using the Rubicon Thruplex library preparations (Rubicon Genomics, USA). Sequencing was done at Science for Life Laboratories (Stockholm, Sweden) using the Illumina HiSeq High Output v4 protocol. The metagenomic samples were trimmed with respect to adapters and low-quality nucleotide stretches using Trim Galore! (http://www. bioinformatics.babraham.ac.uk/projects/trim_galore/) with parameter settings “-retain_unpaired -paired -phred33 -e 0.1 -q 28 -0 10". Trimmed and filtered sequences were used as input for all further analyses. Sequence data has been submitted to the European Nucleotide Archive under project accession number PRJEB11402 (http://www.ebi.ac. uk/ena/data/view/PRJEB11402).

\subsection{Metagenomic analysis of antibiotic resistance genes}

Quality-filtered reads were mapped against the Resqu ARG database (version 1.1; http://www.1928diagnostics.com/resdb; for details, see Bengtsson-Palme et al. (2014)) using Vmatch (http://vmatch.de), allowing two mismatched amino acids per translated read to account for sequencing errors but retain stringency with regards to finding the sought target genes (options "-showdesc 60 -dnavsprot 11 -1 20 -h 2 "), and thus avoiding inflation by false positive matches (Martinez et al., 2015). The number of matches to each ARG was counted and normalized to the length of the respective gene to avoid bias due to differential length of the ARGs. The length-normalized numbers were then used for deriving an approximation of the number of ARGs per bacterial 16S rRNA sequence identified by Metaxa2 (see below), accounting for the average length of the $16 \mathrm{~S}$ gene. ARG copies per bacterial 16S rRNA counts were log-transformed after adding $10^{-8}$ to each abundance number to avoid log-transforming values of zero. Relationships between log-transformed ARG abundances and TC concentration (log- transformed) were assessed using linear regression in the R statistical program (http://www.r-project.org). All p-values were corrected for multiple testing using a Benjamini-Hochberg false discovery rate (FDR) and genes with an FDR $<0.05$ were considered significant (Benjamini and Hochberg, 1995). The statistical significance of the overrepresentation of positive associations between tetracycline concentration and tet resistance genes was assessed using the Wilcoxon rank sum test on the slopes and $\mathrm{R}^{2}$ values of the linear regression. Principal component analysis (PCA) was carried out using R to investigate the relationships between aquaria and ARGs.

\subsection{Metagenomic analysis of taxonomic composition}

Quality filtered read pairs were scanned with Metaxa2 version 2.0 (Bengtsson-Palme et al., 2015a) to extract bacterial 16S rRNA sequences (default options). The resulting $16 \mathrm{~S}$ counts from each sample corresponding to different species, genera, families, order, classes, and phyla were normalized to the total number of 165 sequences identified in that sample, yielding relative abundances for each taxonomic group. The 16S rRNA abundances were log-transformed after adding $10^{-8}$ to each abundance number. Relationships between log-transformed abundances of different taxa and log-transformed TC concentrations were assessed using linear regression in the R statistical program (http:// www.r-project.org). The p-values were corrected for multiple testing using the Benjamini-Hochberg FDR and tests with an FDR $<0.05$ were considered significant. Taxonomic diversity was assessed at the genus level using the R package Vegan (Oksanen et al., 2011), generating Shannon diversity indices (function diversity, index = "shannon"), genus richness (function specnumber) and community evenness (diversity/ln(richness)) numbers. PCA was performed using R to investigate the associations between aquaria and particular genera.

\subsection{Quantitative PCR ( $q P C R$ ) amplification of tetG and tetA genes}

Using qPCR, gene levels of tet $\mathrm{G}$ and tetA were quantified to establish two genotypic MSCs. These two tet genes were selected as targets since they showed the strongest correlation to TC concentration based on the metagenomics analysis in the exposure-response experiment. Bacterial 16S rRNA was used to normalize the results to bacterial abundance. Primer sequences for tet $G$ were $5^{\prime}$-cgctaacgagcctcaccaat- $3^{\prime}$ and $5^{\prime}-$ tgcgaatggtctgcgtagta-3'; and for tetA 5'- ggcactcatgctcggaat-3' and 5'gcaggcagagcaagtagagg- $3^{\prime}$. Primers used for $16 S$ have been previously described (Muyzer et al., 1993). Each reaction contained $1 \times$ Power SYBR ${ }^{\circledR}$ Green PCR Master Mix (Applied Biosystems, USA), 5 ng DNA, and $500 \mathrm{nM}$ of each primer pair in a final reaction volume of $20 \mu \mathrm{L}$. The reaction was performed in 96-well reaction plates (Applied Biosystems, USA) using a 7500 real time PCR system (Applied Biosystems, USA) with a 10 min initial denaturation step at $95{ }^{\circ} \mathrm{C}$, followed by 40 cycles of $95{ }^{\circ} \mathrm{C}$ for $15 \mathrm{~s}$ and $60^{\circ} \mathrm{C}$ for $1 \mathrm{~min}$. A melting curve analysis and gel electrophoresis was performed after each run to verify specific amplification. Significance of increased resistance was determined for the normalized $\log _{2}$ values using a one-tailed Student's $t$ test assuming unequal variance.

\subsection{Measurement of tetracycline concentration}

To accurately measure the TC concentrations within the aquaria a LC-MS/MS method was developed. A full description of the method and validation of the performance can be found in Appendix A. Briefly, $10 \mathrm{~mL}$ of sample were mixed with $4 \mathrm{~mL}$ extraction buffer ( $50 \mathrm{mM}$ acetic acid and 10 mM EDTA in MilliQ water, pH 3.5) and 300 ng of labeled internal standard, tetracycline-D6 (Toronto Research Chemicals, Canada), was added to the sample. Solid phase extraction was performed using Oasis HLB, $200 \mathrm{mg}$ extraction cartridges (Waters, Ireland) for preconcentration and clean-up of sample prior to the LC-MS/MS analysis. Samples were then analyzed on a Thermo TSQ Quantum Ultra EMR 
(Thermo Fisher Scientific, USA) triple stage quadrupole instrument with a heated electrospray ion source (HESI) operated in positive mode at $3.5 \mathrm{kV}$ ionization voltage. An Agilent eclipse Plus C18, $2.1 \times 150 \mathrm{~mm}$, $5 \mu \mathrm{m}$ column (USA) was used and the gradient program can be found in Appendix A, Table A1.

\section{Results}

\subsection{Tetracycline concentrations}

TC concentrations in each aquarium showed good agreement with nominal concentrations (Appendix A; Table A3-A5). Hence, nominal concentrations are referred to in the rest of the paper.

\subsection{Phenotypic profiling of the exposure-response experiment}

To determine possible sensitivity and detection levels of different methods, biofilms were phenotypically profiled using CFU counts, range of measured MIC for isolates, and PICT quantified as inhibition of leucine uptake.

Percentage of TC resistance bacteria seen in the CFU count, increased with increasing TC exposure in a classical exposure-response manner (Fig. 1A). Increase in resistance started at $1-10 \mu \mathrm{g} / \mathrm{L}$, indicating a lower range at which selection occurs that could be used in follow-up experiments with more replication.

The MIC a assays revealed an apparent shift in sensitivity patterns of the isolates at $10-100 \mu \mathrm{g} / \mathrm{L}$. At these TC exposure levels, fewer isolates showed a low MIC, while an increasing number of isolates showed a medium and high MIC, indicating selectivity (Fig. 1B).

Analyses of PICT suggest an increased tolerance at $100 \mu \mathrm{g} / \mathrm{L}$ (Fig. 1C). However, one of the $100 \mu \mathrm{g} / \mathrm{L}$ replicates generated an inhibition curve with different slope to that of all other aquaria (Fig. B2, Appendix B). Although this replicate had an EC50-value that followed the overall response in the experiment, it displayed an altered response to the short-term TC exposure as low concentrations resulted in a stronger inhibition and higher concentrations yielded lower inhibition, compared to all other aquaria. The reason for this remains unknown; therefore, this data point should be viewed with some caution.

\subsection{Genotypic profiling of the exposure-response experiment}

ARGs that significantly correlated with TC exposure concentrations are presented in Table 1, including seven tet genes, six of which increased and one (tet30) that decreased with increasing TC exposure. In total, 26 genes involved in resistance to TC were detected in the study, and these had stronger positive correlations to TC concentration ( $p=0.03019$, Wilcoxon rank sum test for slope) with better exposure-response relationships ( $\mathrm{p}=0.008136$, Wilcoxon rank sum test for $\mathrm{R}^{2}$ ) than ARGs in general. Genes tetG and tetA showed a clear exposure-response with the strongest significances, high abundance (total counts), and highest $\mathrm{R}^{2}$-values. Additionally, ten ARGs that provide resistance to other antibiotics than TC were significantly and positively correlated with the TC exposure concentration (Table 1).

Nine tet genes were present in high abundance within the different aquaria (Fig. 1D), all except tet34 encoding efflux pumps. In the two aquaria exposed to $1000 \mu \mathrm{g} / \mathrm{L}$ TC there was a clear difference between replicates, as an increase of tet 39 and a decrease of tet 42 was seen in one of the two replicates, while the other replicate showed an increase of tetE and tet33. Based on this initial exposure-response experiment, a possible MSC range for selection of the mentioned tet genes was estimated to around 1-10 $\mu \mathrm{g} / \mathrm{L}$ (Fig. 1D). Furthermore, PCA of the ARGs showed that TC exposures of $0,0.1$, and $1 \mu \mathrm{g} / \mathrm{L}$ clustered together,
A

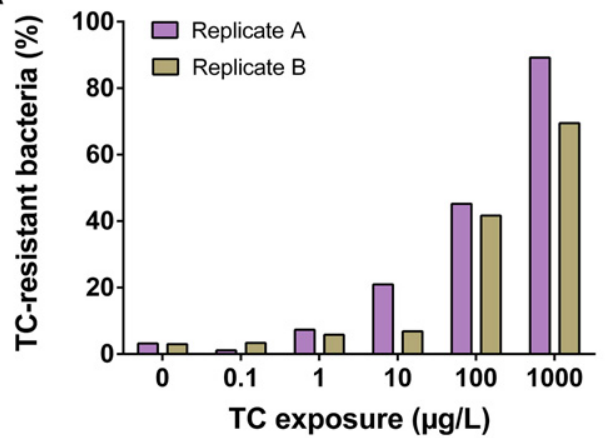

C

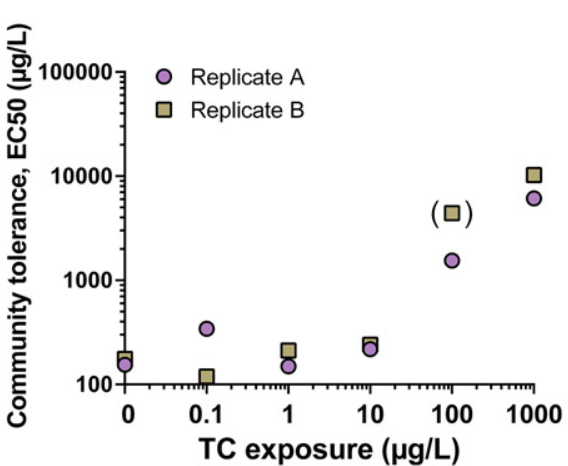

B

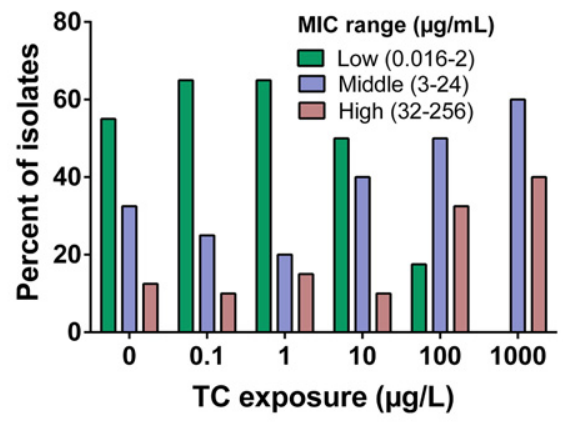

D

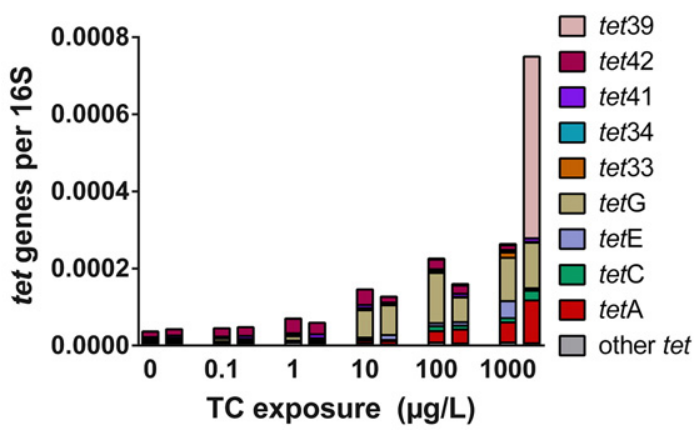

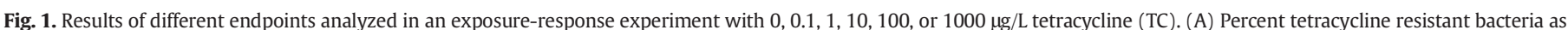

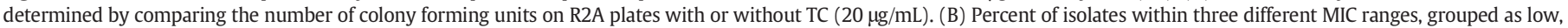

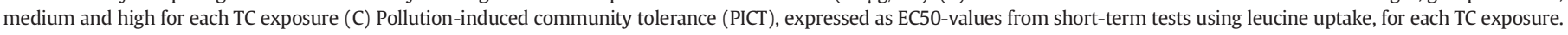

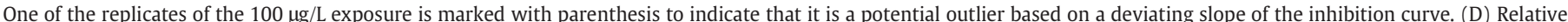

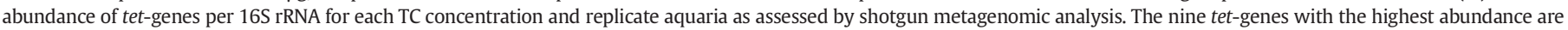

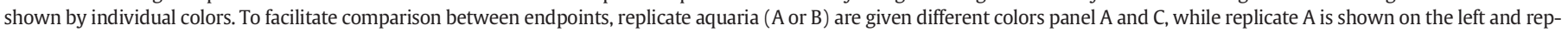
licate $\mathrm{B}$ on the right in the $\mathrm{D}$ panel. 
Table 1

Antibiotic resistance genes with significant correlations to tetracycline concentration after correction for multiple testing using the Benjamini-Hochberg false discovery rate (adjusted p-values $<0.05$ considered significant).

\begin{tabular}{llllll}
\hline Gene & Resistance to & $\begin{array}{l}\text { Total } \\
\text { counts }^{\mathrm{a}}\end{array}$ & $\mathrm{R}^{2}$ & $\begin{array}{l}\text { Adjusted } \\
\text { p-value }\end{array}$ & Slope \\
\hline tetG & Tetracycline & 58,196 & 0.823 & 0.00868 & 0.326 \\
tetA & Tetracycline & 22,645 & 0.798 & 0.00856 & 0.321 \\
tetY & Tetracycline & 568 & 0.772 & 0.01063 & 0.4 \\
cmlA & Multidrug & 1993 & 0.741 & 0.01521 & 0.185 \\
floR & Florfenicol, & 31,026 & 0.739 & 0.01286 & 0.181 \\
& Chloramphenicol & & & & \\
sul1 & Sulfonamide & 4454 & 0.718 & 0.01569 & 0.224 \\
aac6'-Ib & Aminoglycoside & 667 & 0.707 & 0.0166 & 0.31 \\
tetC & Tetracycline & 7775 & 0.696 & 0.01758 & 0.154 \\
mphA & Macrolide & 509 & 0.685 & 0.01878 & 0.276 \\
bla-ACC & B-lactam & 1435 & 0.670 & 0.02133 & 0.084 \\
dfrA7/dfrA17/dfrA32 & Trimethoprim & 25 & 0.662 & 0.02191 & 0.267 \\
aph4-la & Aminoglycoside & 22 & 0.651 & 0.02378 & 0.209 \\
tet30 & Tetracycline & 1395 & 0.646 & 0.02371 & -0.313 \\
tet39 & Tetracycline & 35,597 & 0.625 & 0.02997 & 0.469 \\
vatG & Streptogramin & 57 & 0.608 & 0.03502 & 0.264 \\
tetE & Tetracycline & 9472 & 0.603 & 0.03496 & 0.259 \\
bla-KPC & B-lactam incl. & 44 & 0.571 & 0.04953 & 0.169 \\
& carbapenem & & & & \\
\hline
\end{tabular}

${ }^{a}$ Total counts represent the total number of reads for a particular gene across all 12 samples.

while 10 and $100 \mu \mathrm{g} / \mathrm{L}$ formed a separate cluster (Fig. B3, Appendix B). For exposures of $1000 \mu \mathrm{g} / \mathrm{L}$, one of the replicates clustered close to the 10 and $100 \mu \mathrm{g} / \mathrm{L}$ exposures while the other replicate differed substantially from the rest and this differentiation was driven mainly by tet39 and sul2.

\subsection{Taxonomic analysis of the exposure-response experiment}

Diversity on both a genotypic and functional level was examined in the exposure-response experiment to observe if and at what TC concentration any community changes occurred that could be indicative of a selective pressure of TC.

Based on assignment of extracted small subunit rRNA the biofilms contained mainly bacterial cells (89.4-99.1\%) with a minor contribution from eukaryotic cells (0.55-7.5\%) (Fig. B4, Appendix B). The bacterial fraction showed a trend to decrease with increased TC exposure but this decrease was not statistically significant $(\mathrm{p}=0.057$; linear regression). Other rRNA sequences corresponded to mitochondria (0.02$2.96 \%$ ), chloroplasts (0.0015-0.017\%), and rRNA of unknown origin (0.06-1.61\%). Diversity of the bacterial metagenomes was examined at the genus level using extracted 16S rRNA data (Fig. B5A-C, Appendix $B)$. There was no apparent effect of TC exposure on the overall genus diversity ( $p=0.876$, Fig. B5A, Appendix B), richness ( $p=0.205$, Fig. B5B, Appendix B), or evenness ( $p=0.937$, Fig. B5C, Appendix B) according to linear regression analysis.

Functional diversity was assessed by the utilization of carbon sources (Fig. B5D—F, Appendix B). Diversity ( $p=0.0379$, Fig. B5D, Appendix $B$ ), richness ( $p=0.0397$, Fig. B5E, Appendix $B$ ), and evenness ( $p=0.0388$, Fig. B5F, Appendix B) all decreased significantly with increased TC exposures according to linear regression analysis. Thus, metabolic capacity of the bacterial community seemed to change upon TC exposure, although the genetically based taxonomic diversity was largely maintained.

Despite no apparent change in overall taxonomic diversity, PCA of the abundance of bacterial genera suggests that exposure to increased TC concentrations results in altered community composition (Fig. B6, Appendix B). Taxonomic compositions of the two communities exposed to $1000 \mu \mathrm{g} / \mathrm{L}$ differ substantially, not only from those exposed to lower TC concentrations, but also from each other. In particular, three bacterial genera are driving this differentiation. Pseudomonas associates with the controls $(0 \mu \mathrm{g} / \mathrm{L})$ and low concentrations, while presence of Aeromonas or Acinetobacter appears to be driving the differentiation between the two replicates exposed to $1000 \mu \mathrm{g} / \mathrm{L}$. Changes in the abundances of genera significantly linked to TC exposure occurred primarily within the phylum Proteobacteria (Table 2). There was a biphasic response in the abundance of genera with decreases at a TC range of 1-10 $\mu \mathrm{g} / \mathrm{and}$ increases at 100-1000 $\mu \mathrm{g} / \mathrm{L}$ for increasing genera (Fig. B7, Appendix B).

Combination of the taxonomic data with the tet gene results (Fig. 1D) might explain some unexpected results. In one replicate of the $1000 \mu \mathrm{g} / \mathrm{L}$ exposure, tet39 was present in large quantities. In this sample Acinetobacter was also observed to be highly abundant (Fig. B6, Appendix B). Acinetobacter is a known carrier of tet39 (Agersø and Guardabassi, 2005) and there is a significant positive relationship between tet39 and Acinetobacter within the samples according to linear regression $\left(\mathrm{p}=0.00258 ; \mathrm{R}^{2}=0.6136\right.$; slope $\left.=2.1236\right)$.

\subsection{Establishing minimal selective concentrations using phenotypic and ge- notypic assays}

Based on the indications of differential sensitivity of the endpoints studied in the described exposure-response experiment, we chose to study the percentage of TC-resistant CFUs and changes in the relative abundance of the genes tet $\mathrm{A}$ and tet $\mathrm{G}$ in two follow-up experiments with higher replication, to determine MSCs for these endpoints.

Using relative differences in CFU counts as a phenotypic assay, the MSC for TC was demonstrated to be $10 \mu \mathrm{g} / \mathrm{L}(\mathrm{p}=0.0045)$ resulting in a two-fold increase of growth on TC supplemented plates (Fig. 2A).

In a genotypic assay, relative levels of tet $\mathrm{G}$ and tetA were used, since these two genes showed the strongest correlation to TC concentrations. To improve sensitivity and throughput, qPCR was used to establish MSCs of tetG and tetA gene levels. By comparing qPCR data for tetA with the abundance determined by metagenomics on DNA samples from the first exposure-response experiment, a strong correlation was demonstrated $\left(R^{2}=0.873\right.$, Fig. B8, Appendix B), adding confidence to both methods. Unfortunately, not enough DNA was available to perform a similar comparison for tetG. In the two follow up experiments, qPCR analyses revealed significant increases of tet $\mathrm{G}$ and tetA levels, both at $1 \mu \mathrm{g} / \mathrm{L}$ (Fig. $2 \mathrm{~B} ; \mathrm{p}=0.026$ and 0.005 , respectively) and at $10 \mu \mathrm{g} / \mathrm{L}$ (Fig. 2C; $\mathrm{p}=9.95 \times 10^{-7}$ and 0.017 , respectively). Between experiments, basal levels of both tetA and tet $\mathrm{G}$ levels differ due to the unavoidable variability of the complex inoculum. However, within each experiment the levels of these genes were stable and thereby MSCs could be determined. Since effects were demonstrated at the lowest

Table 2

Bacterial genera with significant correlations to tetracycline concentration after correction for multiple testing using the Benjamini-Hochberg false discovery rate (adjusted p-values $<0.05$ considered significant).

\begin{tabular}{|c|c|c|c|c|c|}
\hline Genus & Class & $\begin{array}{l}\text { Total } \\
\text { counts }^{\mathrm{a}}\end{array}$ & $\mathrm{R}^{2}$ & $\begin{array}{l}\text { Adjusted } \\
\text { p-value }\end{array}$ & Slope \\
\hline Exiguobacterium & Bacilli & 109 & 0.79 & 0.0064 & -0.93 \\
\hline Labrenzia & Alpha-proteobacteria & 179 & 0.78 & 0.0067 & -0.98 \\
\hline $\begin{array}{l}\text { Unclassified } \\
\text { Rhodobacteraceae }\end{array}$ & Alpha-proteobacteria & 3336 & 0.79 & 0.0083 & -0.37 \\
\hline Pannonibacter & Alpha-proteobacteria & 4641 & 0.79 & 0.0116 & -1.15 \\
\hline Acidovorax & Beta-proteobacteria & 44,751 & 0.81 & 0.0144 & -0.60 \\
\hline Albidiferax & Beta-proteobacteria & 873 & 0.70 & 0.0273 & -1.06 \\
\hline Sphingopyxis & Alpha-proteobacteria & 5479 & 0.69 & 0.0294 & -0.49 \\
\hline Dyella & Gamma-proteobacteria & 2056 & 0.67 & 0.0335 & -0.24 \\
\hline $\begin{array}{l}\text { Unclassified } \\
\text { Sphingomonadales }\end{array}$ & Alpha-proteobacteria & 1835 & 0.66 & 0.0340 & -0.25 \\
\hline $\begin{array}{l}\text { Unclassified } \\
\text { Caulobacteraceae }\end{array}$ & Alpha-proteobacteria & 10,152 & 0.64 & 0.0386 & 0.41 \\
\hline Lampropedia & Beta-proteobacteria & 108 & 0.64 & 0.0393 & -0.72 \\
\hline Luteibacter & Gamma-proteobacteria & 1264 & 0.63 & 0.0407 & 0.26 \\
\hline $\begin{array}{l}\text { Unclassified } \\
\text { Alcaligenaceae }\end{array}$ & Beta-proteobacteria & 28,421 & 0.59 & 0.0488 & 0.11 \\
\hline
\end{tabular}

a Total counts represent the total number of reads for a particular genus across all 12 samples. 
A

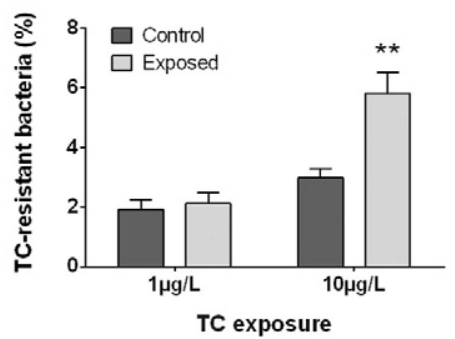

B

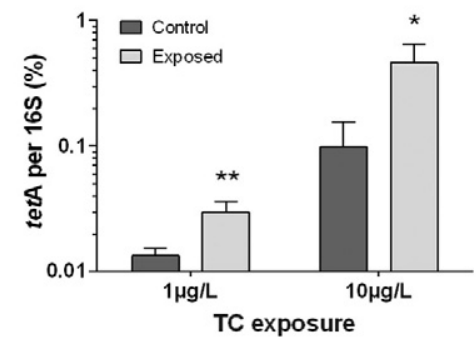

C

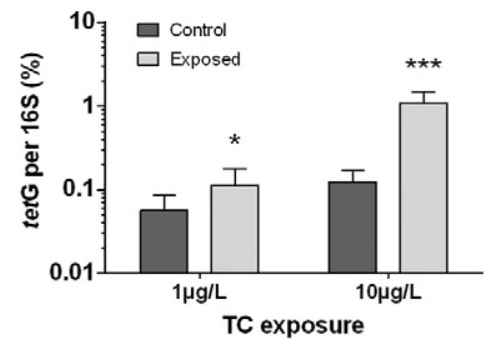

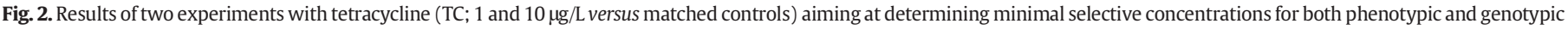

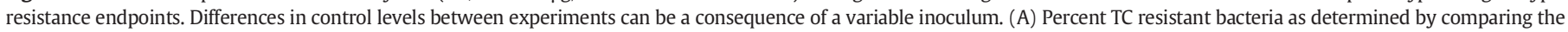

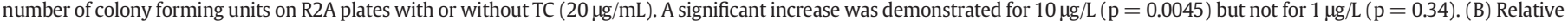

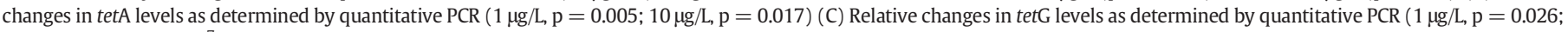

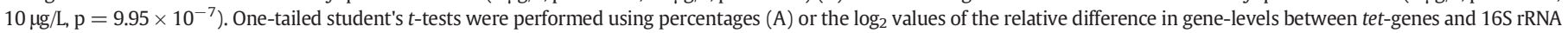
$(\mathrm{B}, \mathrm{C})$. Significance indicated as follows: ${ }^{*}, \mathrm{p}<0.05$; $^{* *}, \mathrm{p}<0.01$; $^{* * *}, \mathrm{p}<0.001$.

tested concentration, the MSCs for both tetG and tetA were determined to be $\leq 1 \mu \mathrm{g} / \mathrm{L}$.

\section{Discussion}

To our best knowledge, this is the first study to thoroughly examine the selective properties of an antibiotic in a complex bacterial community, by defining MSCs using both phenotypic and genotypic endpoints. Selective effects of TC are observed on phenotypic, genotypic, and taxonomic levels in a concentration range as low as $\leq 1-10 \mu \mathrm{g} / \mathrm{L}$. This overlaps with measured concentrations of TC in certain aquatic environments, indicating a risk for selection of resistance.

Both phenotypic (CFU count) and genotypic (qPCR) assays were performed, but obtained MSCs from these two methods differed. MSCs based on qPCR of tetG and tetA levels were lower than the MSC based on CFU counts ( $\leq 1 \mu \mathrm{g} / \mathrm{L}$ compared to $10 \mu \mathrm{g} / \mathrm{L}$ ). A plausible reason is that many tetA and tetG carriers were not able to grow on R2A media. Alternatively (or additionally), it could be caused by tet genes providing insufficient resistance to allow growth on plates supplemented with TC. It is also possible that the fraction of colony forming bacteria carrying tetA or tet $\mathrm{G}$ genes is so small that the increase of those bacteria at $1 \mu \mathrm{g} / \mathrm{L}$ is masked by the presence of bacteria carrying other resistance factors, including features that make them intrinsically resistant to tetracycline. In any case, the most important factor in determining the method for defining MSCs is perhaps to scrutinize the relevance of the investigated endpoints. In this case, we consider the MSCs of tetA and tet $\mathrm{G}$ to be highly relevant as these endpoints demonstrate selectivity on a genetic level that increase horizontally transferrable resistance factors, which is a process of high concern (Martinez et al., 2015).

Genotypic assays used here were shotgun metagenomics and qPCR analysis, which in this study complemented each other to determine MSCs based on gene abundance. Metagenomic analysis was crucial in order to define which tet genes increased in abundance during the exposure-response experiment, while qPCR was used in the two later MSC experiments as a sensitive and cost-effective assay to determine the relative abundance of these genes (tet $\mathrm{G}$ and tetA). Due to the differences in cost between a metagenomic and qPCR analysis one might consider performing only a qPCR to determine MSCs. This is an option in cases when only a few known ARGs are likely to provide a resistance phenotype (e.g. sul1, sul2, and sul3 providing resistance to sulfonamides), but less so when a resistance phenotype to a given antibiotic could be caused by a wide variety of genes (e.g. beta-lactamase genes). Using an exploratory assay like metagenomics has additional advantages, in spite of a higher cost, as unexpected effects like coselection of other ARGs (Table 1), taxonomic shifts (Table 2), or even new potential ARGs can be discovered (given sufficient resemblance to known ARGs). On the downside, fragmented DNA present in e.g. the extracellular matrix (eDNA) of biofilms might influence the results of genetically based assays.

Three different phenotypic assays (CFU counts on selective media, MIC range of isolates, and PICT) were used in the exposure-response experiment. While we did not perform a strict comparison, effect concentrations appear to differ between endpoints. The lowest effect concentration was obtained by the CFU counts $(1-10 \mu \mathrm{g} / \mathrm{L})$ followed by MIC range (10-100 $\mu \mathrm{g} / \mathrm{L})$ and PICT $(100 \mu \mathrm{g} / \mathrm{L})$. Both CFU count and MIC range are dependent on the cultivable part of the communities, which in turn is defined by the growth conditions used. Furthermore, $\mathrm{CFU}$ count is stringently defined around a specific pre-determined concentration of TC (in this study $20 \mu \mathrm{g} / \mathrm{mL}$ ). Using a high concentration could favor intrinsically resistant bacteria whereas resistance provided by a tet gene might not be sufficient to allow growth on such media. This may have been an issue for the CFU count for Quinlan et al. (2011) as they used a relatively high TC concentration $(100 \mu \mathrm{g} / \mathrm{mL})$, greatly exceeding all known clinical breakpoints for TC in different species (1-4 $\mu \mathrm{g} / \mathrm{mL}$; EUCAST breakpoints v5.0). Using a very low selective concentration may, on the other hand, result in increased background noise and effects of a tet gene might therefore not be detectable. Sensitivity of a MSC based on MIC range is not dependent on a predetermined cut-off concentration, as is the CFU assay, but the throughput in terms of investigated colonies per effort is considerably lower. In addition, the MIC range assay cause additional stringency in cultivability as it requires isolates to grow on $\mathrm{MH}$ agar and broth at a specific temperature. A PICT assay reflects changes in the abundance of sensitive and resistant/tolerant species or strains within the community (Blanck, 2002). PICT was detected with the measurement of leucine uptake. Thus, its detection is based on a metabolic and phenotypic process that is not limited by the cultivability on agar or broth. In this study, PICT appeared to be comparably insensitive. If leucine uptake is not homogenous among bacterial species (Ruiz-González et al., 2012), selective concentrations determined through PICT might become highly dependent on the TC tolerance of the portion of the community that has the most effective leucine uptake.

While the overall taxonomic diversity did not change as a result of the TC exposure (according to used indices) there were still discernible changes when exploring potential effects on specific genera, appearing at $1-10 \mu \mathrm{g} / \mathrm{L}$ (decreasing genera). Importantly, the genus diversity and richness did not significantly decrease at higher concentrations of tetracycline, suggesting that sensitive genera are replaced by a similar number of tolerant genera. Lower sensitivity of diversity endpoints compared to community composition is a common pattern when communities are exposed to toxicants (e.g. see Berg et al., 2012). Loss of species could open niches that resistant species competed for and won, thereby influencing the range at which MSC occurs. Furthermore, we detected effects of TC exposure on the functional diversity based on the ability of the communities to utilize different carbon sources. This 
could be indicative of species with certain phenotypes disappearing at higher TC concentrations. In summary, one could argue that MSCs in complex communities are influenced by the most susceptible bacteria as decrease in their abundance will open up niches that resistant bacteria can compete for.

Tetracycline concentrations of $\leq 1 \mu \mathrm{g} / \mathrm{L}$ selected for both tetA and tet $G$ genes. Selection of tetA and tetG has previously been reported when exposing activated sludge bacteria, diluted in filtrated sewage influent, to very high concentrations of TC ( 5 and $20 \mathrm{mg} / \mathrm{L}$ ) for six days (Huang et al., 2014). This indicates some degree of robustness of tetA and tetG as markers for a selection pressure from tetracycline. However, in the study by Huang et al. (2014), no effect on either gene was seen at $1 \mathrm{mg} / \mathrm{L}$, the lowest concentration tested. It is unclear if this is a reflection of limited bioavailability of TC, use of an already established community in the assay, and/or fewer bacterial generations studied. Selection of tetA was also observed in the fecal bacterial communities of mice given water supplemented with $10 \mathrm{mg} / \mathrm{L} \mathrm{TC}$ compared to control mice (Yin et al., 2015). Selection of tetG did not occur in this case, which might be related to e.g. the difference in community composition. Two studies investigated tetA selection specifically, using competition between two Escherichia coli strains and determined the MSC of TC to be $62.5 \mu \mathrm{g} / \mathrm{L}$ (Liu et al., 2011) or $15 \mu \mathrm{g} / \mathrm{L}$ (Gullberg et al., 2011). Compared to these studies, selection of tetA occurred at lower concentration in the complex bacterial communities used here. The community based assay likely involves many different bacteria in which carrying tetA involve variable levels of fitness costs and levels of resistance, thereby providing a plausible explanation behind the higher sensitivity.

Empirically derived MSCs for TC obtained in our study overlapped with theoretically predicted MSCs based on available MICs for many species (Bengtsson-Palme and Larsson, 2016). Indeed, the phenotypic endpoint based on CFU counts was identical to the predicted no effect concentration of TC (Bengtsson-Palme and Larsson, 2016), whereas the genetically based endpoints (tetA and tet $\mathrm{G}$ genes) were more sensitive. It is possible that genetic resistance markers are consistently more sensitive than culture-based endpoints, but to allow generalizations, this has to be evaluated for more antibiotics.

Since our goal was to design a sensitive assay, important aspects to consider was the founder effect (Kelly et al., 2014) as well as reduced antibiotic sensitivity due to e.g. extracellular matrix formation in biofilms (Høiby et al., 2010). Rather than exposing already established communities, biofilms were allowed to form during TC exposure, allowing selection during both the colonization and growth stages. Nevertheless, effects of TC have previously been reported in a study using already established biofilms in five stream mesocosms. A significant increase in TC resistance was reported at $0.5 \mu \mathrm{g} / \mathrm{L}$ using CFU counts (Quinlan et al., 2011), compared with $10 \mu \mathrm{g} / \mathrm{L}$ in our setup. However, the results from the stream mesocosms did not follow an exposureresponse pattern which would be expected if there was a direct link between exposure (cause) and relative increase of TC-resistance based on CFU counts (effect). In our study, a classical exposure-response pattern was observed. In follow up experiments we used extensive replication of aquaria to define the MSCs. Due to an elaborate experimental design Quinlan et al. (2011) did not replicate the mesocosm exposures $(\mathrm{n}=1$ ). Thus, it is possible that the reported significant resistance increase at $0.5 \mu \mathrm{g} / \mathrm{L}$ in the stream mesocosm experiment could be a result of pseudo-replication. To some degree, MSCs are expected to vary between experimental setups. However, given the clear exposureresponse and statistical replication, we have more trust in the CFUbased MSC generated in our study. In summary, complex bacterial communities can be argued to be more relevant for risk assessments than studies on individual strains, but the use of complex systems might be subjected to multiple unknown selective or disrupting factors interfering with observed effects. Hence, it is important to link cause and effect through several causation criteria like e.g. exposure-response, consistency in replication, mechanistic understanding and effect size as described in for example "Hills criteria of causation" (Hill, 1965).
By comparisons with environmental concentrations of TC, the results obtained in this study could contribute to risk assessments (Ashbolt et al., 2013). Concentrations as high as $1 \mu \mathrm{g} / \mathrm{L}$ are not uncommon in untreated sewage (Karthikeyan and Meyer, 2006; Lindberg et al., 2014). In surface water, concentrations are generally much lower (Kolpin et al., 2002), partly because TC has a high sorption to sediments (Bai et al., 2014). Nevertheless, high levels of TC (50 $\mu \mathrm{g} / \mathrm{L}$ ) have been found downstream from fish farms in Turkey (Topal and Arslan Topal, 2015). At such sites, and possibly within sewage treatment plants, selection is likely to occur given the MSCs obtained in the current study. However, bioavailability varies between matrixes (Sassman and Lee, 2005), providing additional challenges to extrapolate results from laboratory conditions to different external environments.

Observed increases of tetA and tetG genes in this study might be interpreted as a cause for concern with regards to human health risks. However, tetracycline resistance genes, including tetA, are already found in high abundance in the bacterial communities of human feces (Bengtsson-Palme et al., 2015b) and the potential human health risk coupled to elevated tetA levels in environmental compartments could therefore be debated (Bengtsson-Palme and Larsson, 2015). Nonetheless, increase of tetA (and tet $\mathrm{G}$ ) demonstrates that TC has the ability to select for resistance on a genetic level that could potentially lead to increase of unknown genes conferring TC-resistance or multi-resistance within the environmental resistome. Another risk scenario is coselection (Table 1), which could cause increases of ARGs less abundant or absent in the bacterial communities of human feces.

In conclusion, the present study demonstrates methods to determine MSCs of an antibiotic in a complex bacterial community. The MSCs generated here for TC, and those that in the future could be established for other antibiotics, could aid in developing regulations or guidelines for safe emission limits that take risks for resistance development into account (Ashbolt et al., 2013; Ågerstrand et al., 2015; Bengtsson-Palme and Larsson, 2016; Jutkina et al., 2016). Such data can also aid in finding potential hot-spots for resistance selection in the environment where mitigating actions may be warranted.

\section{Acknowledgments}

Funding was provided by the Swedish Foundation for Strategic Environmental Research (MISTRA, MistraPharma), the Swedish Research Council FORMAS (grant no 2015-750), the Swedish Research Council VR (grant no 2015-02492), and the Knut and Alice Wallenberg Foundation. We thank Gryaab AB, Ryaverket (Gothenburg, Sweden) for providing treated sewage effluent. Furthermore, the authors acknowledge support from Science for Life Laboratory, the National Genomics Infrastructure funded by the Swedish Research Council, and Uppsala Multidisciplinary Center for Advanced Computational Science for assistance with massively parallel sequencing and access to the UPPMAX computational infrastructure.

\section{Appendix A and B. Supplementary data}

Supplementary data to this article can be found online at http://dx. doi.org/10.1016/j.scitotenv.2016.02.103.

\section{References}

Agersø, Y., Guardabassi, L., 2005. Identification of Tet 39, a novel class of tetracycline resistance determinant in Acinetobacter spp. of environmental and clinical origin. J. Antimicrob. Chemother. 55 (4), 566-569.

Ågerstrand, M., Berg, C., Björlenius, B., Breitholtz, M., Brunström, B., Fick, J., Gunnarsson, L. Larsson, D.G.J., Sumpter, J.P., Tysklind, M., Rudén, C., 2015. Improving environmental risk assessment of human pharmaceuticals. Environ. Sci. Technol. 49 (9), 5336-5345.

Agwuh, K.N., MacGowan, A., 2006. Pharmacokinetics and pharmacodynamics of the tetracyclines including glycylcyclines. J. Antimicrob. Chemother. 58, 256-265.

Andersson, D.I., Hughes, D., 2014. Microbiological effects of sublethal levels of antibiotics. Nat. Rev. Microbiol. 12, 465-478.

Ashbolt, N.J., Amezquita, A., Backhaus, T., Borriello, P., Brandt, K.K., Collignon, P., Coors, A. Finley, R., Gaze, W.H., Heberer, T., Lawrence, J.R., Larsson, D.G.J., McEwen, S.A., Ryan, 
J.J. Schönfeld, J., Silley, P., Snape, J.R., Van den Eede, C., Topp, E., 2013. Human Health Risk Assessment (HHRA) for environmental development and transfer of antibiotic resistance. Environ. Health Perspect. 121 (9), 993-1001.

Bai, Y., Meng, W., Xu, J., Zhang, Y., Guo, C., 2014. Occurrence, distribution and bioaccumulation of antibiotics in the Liao River Basin in China. Environ. Sci. Processes Impacts 16 (3), 586-593.

Bengtsson-Palme, J., Larsson, D.G.J., 2015. Antibiotic resistance genes in the environment: prioritizing risks. Nat. Rev. Microbiol. 13 (6), 396.

Bengtsson-Palme, J., Larsson, D.G.J., 2016. Concentrations of antibiotics predicted to select for resistant bacteria: proposed limits for environmental regulation. Environ. Int. 86, 140-149.

Bengtsson-Palme, J., Boulund, F., Fick, J., Kristiansson, E., Larsson, D.G.J., 2014. Shotgun metagenomics reveals a wide array of antibiotic resistance genes and mobile elements in a polluted lake in India. Front. Microbiol. 5, 648.

Bengtsson-Palme, J., Hartmann, M., Eriksson, K.M., Pal, C., Thorell, K., Larsson, D.G.J. Nilsson, R.H., 2015a. Metaxa2: improved identification and taxonomic classification of small and large subunit rRNA in metagenomic data. Mol. Ecol. Resour. 15 (6), 1403-1414.

Bengtsson-Palme, J., Angelin, M., Huss, M., Kjellqvist, S., Kristiansson, E., Palmgren, H. Larsson, D.G.J., Johansson, A., 2015b. The human gut microbiome as a transporter of antibiotic resistance genes between continents. Antimicrob. Agents Chemother. 59 (6), 6551-6560.

Benjamini, Y., Hochberg, Y., 1995. Controlling the false discovery rate: a practical and powerful approach to multiple testing. J. R. Stat. Soc. Ser. B Methodol. 57, 289-300.

Berg, J., Brandt, K.K., Al-Soud, W.A., Holm, P.E., Hansen, L.H., Sorensen, S.J., Nybroe, O. 2012. Selection for $\mathrm{Cu}$-tolerant bacterial communities with altered composition, but unaltered richness, via long-term Cu exposure. Appl. Environ. Microbiol. 78 (20), $7438-7446$

Blanck, H., 2002. A critical review of procedures and approaches used for assessing pollution-induced community tolerance (PICT) in biotic communities. Hum. Ecol. Risk. Assess. 8 (5), 1003-1034.

Brandt, K.K., Amézquita, A., Backhaus, T., Boxall, A., Coors, A., Heberer, T., Lawrence, J.R. Lazorchak, J., Schönfeld, J., Snape, J.R., Zhu, Y.G., Topp, E., 2015. Ecotoxicological assessment of antibiotics: a call for improved consideration of microorganisms. Environ. Int. http://dx.doi.org/10.1016/j.envint.2015.09.013.

Brosche, S., Backhaus, T., 2010. Toxicity of five protein synthesis inhibiting antibiotics and their mixture to limnic bacterial communities. Aquat. Toxicol. 99 (4), 457-465.

Coenen, S., Adriaenssens, N., Versporten, A., Muller, A., Minalu, G., Faes, C. Vankerckhoven, V., Aerts, M., Hens, N., Molenberghs, G., Goossens, H., ESAC Project Group, 2011. European surveillance of antimicrobial consumption (ESAC): outpatien use of tetracyclines, sulphonamides and trimethoprim, and other antibacterials in Europe (1997-2009). J. Antimicrob. Chemother. 66 (6), vi57-vi70.

Davies, J., Davies, D., 2010. Origins and evolution of antibiotic resistance. Microbiol. Mol Biol. Rev. 74 (3), 417-433.

D'Costa, V.M., King, C.E., Kalan, L., Morar, M., Sung, W.W.L., Schwarz, C., Froese, D., Zazula G., Calmels, F., Debruyne, R., Golding, G.B., Poinar, H.N., Wright, G.D., 2011. Antibiotic resistance is ancient. Nature 477 (7365), 457-461.

Elmund, G.K., Morrison, S.M., Grant, D.W., Nevins, S.M., 1971. Role of excreted chlortetracycline in modifying the decomposition process in feedlot waste. Bull. Environ. Contam. Toxicol. 6 (2), 129-132.

Gullberg, E., Cao, S., Berg, O.G., Ilback, C., Sandberg, L., Hughes, D., Andersson, D.I., 2011. Selection of resistant bacteria at very low antibiotic concentrations. PLoS Pathog. 7 (7), e1002158.

Hill, A.B., 1965. The environment and disease: association or causation? Proc. R. Soc. Med. $58,295-300$.

Høiby, N., Bjarnsholt, T., Givskov, M., Molin, S., Ciofu, O., 2010. Antibiotic resistance of bacterial biofilms. Int. J. Antimicrob. Agents 35, 322-332.

Huang, K., Tang, J., Zhang, X.-X., Xu, K., Ren, H., 2014. A comprehensive insight into tetracycline resistant bacteria and antibiotic resistance gene in activated sludge using next-generation sequencing. Int. J. Mol. Sci. 15 (6), 10083-10100.

Jutkina, L., Rutgersson, C., Flach, C.-F., Larsson, D.G.J., 2016. An assay for determining minimal concentrations of antibiotics that drive horizontal transfer of resistance. Sci. Total Environ. 548-549, 131-138.

Karthikeyan, K.G., Meyer, M.T., 2006. Occurrence of antibiotics in wastewater treatment facilities in Wisconsin, USA. Sci. Total Environ. 361, 196-207.
Kelly, J.J., Minalt, N., Culotti, A., Pryor, M., Packman, A., 2014. Temporal variations in the abundance and composition of biofilm communities colonizing drinking water distribution pipes. PLoS One 9 (5), e98542.

Kolpin, D.W., Furlong, E.T., Meyer, M.T., Thurman, E.M., Zaugg, S.D., Barber, L.B., Buxton, H.T. 2002. Pharmaceuticals, hormones, and other organic wastewater contaminants in US streams, 1999-2000: a national reconnaissance. Environ. Sci. Technol. 36 (6), 1202-1211.

Kools, S.A., Moltmann, J.F., Knacker, T., 2008. Estimating the use of veterinary medicines in the European Union. Regul. Toxicol. Pharmacol. 50 (1), 59-65.

Larsson, D.G.J., 2014. Pollution from drug manufacturing: review and perspectives. Philos. Trans. R. Soc. B 369, 20130571.

Lindberg, R.H., Ostman, M., Olofsson, U., Grabic, R., Fick, J., 2014. Occurrence and behavior of 105 active pharmaceutical ingredients in sewage waters of a municipal sewer collection system. Water Res. 58, 221-229.

Liu, A, Fong, A., Becket, E, Yuan, J., Tamae, C., Medrano, L, Maiz, M., Wahba, C. Lee, C., Lee, K., Tran, K.P., Yang, H., Hoffman, R.M., Salih, A., Miller, J.H., 2011. Selective advantage of resistant strains at trace levels of antibiotics: a simple and ultrasensitive color test for detection of antibiotics and genotoxic agents. Antimicrob. Agents Chemother. 55 (3), 1204-1210

Martinez, J.L., Coque, T.M., Baquero, F., 2015. What is a resistance gene? Ranking risk in resistomes. Nat. Rev. Microbiol. 13, 116-123.

Muyzer, G., de Waal, E.C., Uitterlinden, A.G., 1993. Profiling of complex microbial populations by denaturing gradient gel electrophoresis analysis of polymerase chain reaction-amplified genes coding for 16S rRNA. Appl. Environ. Microbiol. 59 (3), 695-700.

Oksanen, J., Blanchet, F.G., Kindt, R., Legendre, P., Minchin, P.R., OHara, R.B., Simpson, G.L., Solymos, P., Stevens, M.H.H., Wagner, H., 2011. Vegan: Community Ecology Package. Pruden, A., Larsson, D.G.J., Amézquita, A., Collignon, P., Brandt, K.K., Graham, D.W., Lazorchak, J.M., Suzuki, S., Silley, P., Snape, J.R., Topp, E., Zhang, T., Zhu, Y.G., 2013. Management options for reducing the release of antibiotics and antibiotic resistance genes to the environment. Environ. Health Perspect. 121 (8), 878-885.

Quinlan, E.L., Nietch, C.T., Blocksom, K., Lazorchak, J.M., Batt, A.L., Griffiths, R., Klemm, D.J., 2011. Temporal dynamics of periphyton exposed to tetracycline in stream mesocosms. Environ. Sci. Technol. 45 (24), 10684-10690.

Rizzo, L., Manaia, C., Merlin, C., Schwartz, T., Dagot, C., Ploy, M.C., Michael, I., FattaKassinos, D., 2013. Urban wastewater treatment plants as hotspots for antibiotic resistant bacteria and genes spread into the environment: a review. Sci. Total Environ. 447, 345-360.

Ruiz-González, C., Lefort, T., Massana, R., Simó, R., Gasol, J.M., 2012. Diel changes in bulk and single-cell bacterial heterotrophic activity in winter surface waters of the northwestern Mediterranean Sea. Limnol. Oceanogr. 57 (1), 29-42.

Sassman, S.A., Lee, L.S., 2005. Sorption of three tetracyclines by several soils: assessing the role of pH and cation exchange. Environ. Sci. Technol. 39 (19), 7452-7459.

Segura, P.A., Francois, M., Gagnon, C., Sauve, S., 2009. Review of the occurrence of antiinfectives in contaminated wastewaters and natural and drinking waters. Environ. Health Perspect. 117 (5), 675-684.

Szczepanowski, R., Linke, B., Krahn, I., Gartemann, K.-H., Gützkow, T., Eichler, W., Pühler, A., Schlüter, A., 2009. Detection of 140 clinically relevant antibiotic-resistance genes in the plasmid metagenome of wastewater treatment plant bacteria showing reduced susceptibility to selected antibiotics. Microbiology 155, 2306-2319.

Topal, M., Arslan Topal, E.I., 2015. Investigation of tetracycline and degradation products in Euphrates river receiving outflows of trout farms. Aquac. Res. http://dx.doi.org/ 10.1111/are.12834.

Watkinson, A.J., Murby, E.J., Kolpin, D.W., Costanzo, S.D., 2009. The occurrence of antibiotics in an urban watershed: from wastewater to drinking water. Sci. Total Environ. 407 (8), 2711-2723.

Ye, L., Zhang, T., 2013. Bacterial communities in different sections of a municipal wastewater treatment plant revealed by $16 \mathrm{~S}$ rDNA 454 pyrosequencing. Appl. Microbiol. Biotechnol. 97, 2681-2690.

Yin, J., Zhang, X.-X., Wu, B., Xian, Q., 2015. Metagenomic insights into tetracycline effects on microbial community and antibiotic resistance of mouse gut. Ecotoxicology http:// dx.doi.org/10.1007/s10646-015-1540-7. 